Revista Universo Contábil, ISSN 1809-3337

UNIVERSO

Blumenau, v. 10, n. 3, p. 44-64, jul./set., 2014

doi:10.4270/ruc.2014319

;

Disponível em www.furb.br/universocontabil

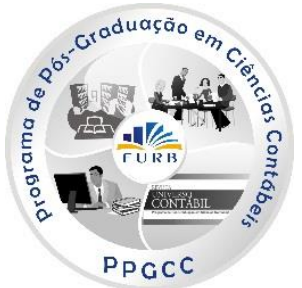

TRIDIMENSIONALIDADE DA LINGUAGEM CONTÁBIL EM PUBLICAÇÕES DE PERIÓDICOS CIENTÍFICOS BRASILEIROS 1

\title{
ACCOUNTING LANGUAGE TRIDIMENSIONALITY IN PUBLICATIONS OF BRAZILIAN SCIENTIFIC JOURNAL
}

\section{TRIDIMENSIONALIDAD DE LA LENGUAJE CONTABLE EN PUBLICACIONES DE REVISTAS CIENTÍFICAS BRASILEÑAS}

Josilene da Silva Barbosa Mestre em Ciências Contábeis pela Universidade Federal do Paraná - UFPR

Professora do Curso de Ciências Contábeis da Universidade Federal de Uberlândia - UFU Endereço: Campus Pontal, Rua 20, 1600 - Tupã CEP: 38304-402 - Ituiutaba - MG E-mail: jslene@hotmail.com

Fone: (34) 3271-5260

Luciana Klein Doutoranda em Ciências Contábeis na Universidade Federal do Paraná - UFPR Campus III, Setor de Ciências Sociais Aplicadas, $1^{\circ}$ Andar Endereço: Av. Lothário Meissner, 632 - Jardim Botânico CEP: 80210-070 - Curitiba - PR E-mail: lucianaklein.ufpr@gmail.com Fone: (41) 3360-4411

Romualdo Douglas Colauto

Doutor em Engenharia de Produção pela EPS/UFSC Professor do Programa de Pós-Graduação em Ciências Contábeis da Universidade Federal do Paraná

Campus III - Setor de Ciências Sociais Aplicadas Endereço: Av. Prefeito Lothário Meissner, 632 - Jardim Botânico CEP: 80210-070 - Curitiba - PR E-mail: rdcolauto.ufpr@gmail.com Fone: (41) 3360-4411

Ilse Maria Beuren

Doutora em Controladoria e Contabilidade pela FEA/USP Professora do Programa de Pós-Graduação em Ciências Contábeis da Universidade Federal do Paraná Campus III - Setor de Ciências Sociais Aplicadas Endereço: Av. Prefeito Lothário Meissner, 632 - Jardim Botânico CEP: 80210-070 - Curitiba - PR E-mail: ilse.beuren@gmail.com Fone: (41) 3060-4386

\footnotetext{
1 Artigo recebido em 16.08.2013. Revisado por pares em 11.05.2014. Reformulado em 17.09.204. Recomendado para publicação em 23.09.2014 por Carlos Eduardo Facin Lavarda. Publicado em 30.09.2014. Organização responsável pelo periódico: FURB.
} 


\section{RESUMO}

A contabilidade, enquanto linguagem do mundo dos negócios, pode ser abordada nas perspectivas sintática, semântica ou pragmática. De modo não explícito, pesquisadores utilizam-se da tridimensionalidade da linguagem contábil para sustentar suas investigações. Este estudo investiga a linguagem contábil adotada na sustentação teórica de publicações em periódicos científicos brasileiros no período 2001-2012, relativas às áreas de Contabilidade para Usuários Externos e de Mercados Financeiro, de Crédito e de Capitais. Para isso, foi realizado um estudo descritivo utilizando Análise de Conteúdo. Os resultados mostram que as linguagens semântica e pragmática se sobressaem à linguagem sintática. Os artigos relacionados à temática Contabilidade para Usuários Externos utilizam mais a abordagem pragmática; e da área de Mercados empregam, principalmente, a abordagem semântica. As pesquisas sobre convergências de normas utilizaram preponderantemente a abordagem sintática, o que se justifica pela necessidade de explicar procedimentos normativos e práticos. As relativas às Finanças Corporativas priorizaram a abordagem semântica, denotando preocupação com o significado das informações produzidas pela contabilidade. As pesquisas sobre temáticas que envolvem o Balanço Social utilizaram mais a abordagem pragmática, com foco na utilidade e reflexos dessas informações no ambiente empresarial. Assim, este estudo contribui na medida em que revela tendências de investigações em temáticas da Contabilidade, particularmente nas áreas focalizadas na análise, quanto aos tipos de abordagem da linguagem utilizada no desenvolvimento dos estudos, propondo uma metodologia que permita classificar os estudos de modo a evidenciar o tipo de abordagem.

Palavras-chave: Contabilidade como linguagem. Sintática. Pragmática. Semântica.

\section{ABSTRACT}

Accounting, as the language of the business world, can be approached in syntactic, semantic, or pragmatic perspectives. Not explicit, the researchers use the tridimensionality of accounting language to support their investigations. This study investigates the accounting language adopted in the theoretical underpinning of publications of Brazilian scientific journals in the period from 2001 to 2012, regarding to the areas of Accounting for External Users and Financial, Credit and Capital Markets. To this end, a descriptive study using Content Analysis were performed. The results show that semantic and pragmatic languages excel syntactic languages. Articles regarding Accounting theme for External Users use more pragmatic approach and the ones of Markets use, mainly, semantic approach. Research on standards convergence used, mainly, syntactic approach, which is justified by the need to explain normative and practical procedures. Those regarding Corporate Finances prioritized the semantic approach, showing concern with the meaning of the information produced by the accounting. The research on issues involving the Social Balance used more pragmatic approach, focusing on the utility and reflexes of such information on the business environment. Thus, this study contributes to the extent that reveals trends in thematic investigations of accounting, particularly in focused areas in the analysis, the types of language used in the development of studies approach, proposing a methodology to classify the studies in order to identify the approach.

Keywords: Accounting as a language. Syntactic. Pragmatic. Semantic.

\section{RESUMEN}

La Contabilidad, como el lenguaje del mundo de los negocios, se puede abordar de perspectivas sintáctica, semántica o pragmática. No explícitamente, los investigadores pueden utilizar es la tridimensionalidad del lenguaje contable para apoyar sus investigaciones. Este estudio investiga el lenguaje contable adoptada en la base teórica de las 
publicaciones en revistas científicas brasileñas en el período 2001-2012, en relación con las áreas de Contabilidad para los usuarios externos y los mercados financiero, de crédito y de capital. Para esto, fue realizado un estudio descriptivo mediante Análisis de Contenido. Los resultados muestran que los lenguajes semánticos y pragmáticos se sobresalen al lenguaje sintáctico. Artículos relacionados con el tema contabilidad para usuarios externos utilizaran enfoque más pragmático y de la área de mercados emplean enfoque fundamentalmente semántico. Las investigaciones sobre la convergencia de las normas utilizaran principalmente el enfoque sintáctico, que se justifica por la necesidad de explicar los procedimientos normativos y prácticos. Las relativas a finanzas corporativas tienen priorizado el enfoque semántico, mostrando preocupación por el significado de la información producida por la contabilidad. Las investigaciones sobre temas relacionados con el Balance Social utilizaran más el enfoque pragmático, centrándose en la utilidad y en los reflejos de esa información sobre el entorno empresarial. Así, este estudio contribuye en la medida en que revela las tendencias en las investigaciones temáticas de contabilidad, especialmente en áreas centradas en el análisis, los tipos de lenguaje utilizados en el desarrollo del enfoque de los estudios, proponiendo una metodología para clasificar los estudios con el fin de identificar el enfoque.

Palabras clave: Contabilidad como lenguaje. Sintáctica. Pragmática. Semántica

\section{INTRODUÇÃO}

As informações são transmitidas e recebidas utilizando-se de métodos específicos, os quais são denominados de comunicação (FERREIRA, 1986). Comunicação é o entendimento interpessoal, participação intencional ou socialização de informações com ajuda de sinais, sistemas de signos, sobretudo, por meio da linguagem (LEWANDOWSKI, 1982). A contabilidade compreende um processo de comunicação, ou seja, é a linguagem dos negócios (LAVOIE, 1987; ILUFI, 2000; KILLIAN, 2010). O entendimento da contabilidade como uma linguagem de negócios decorre de suas semelhanças com as características da linguagem comum, em especial em função de que algumas de suas regras estão definidas e outras não.

Ilufi (2000) expõe que se não houver compreensão da mensagem por parte do usuário, não será concretizada a comunicação. $\mathrm{O}$ ato de comunicar abrange três fatores principais: a fonte, a mensagem e o destino. A fonte produz a mensagem, em que um transmissor a codifica e a transforma em signos. Em seguida, o receptor decodifica os signos e recompõe a mensagem para que o destinatário a receba (SHANNON; WEAVER, 1949). O processo de comunicação na contabilidade começa com a disponibilização de dados por parte das empresas (fonte). Esses dados formam os relatórios contábeis (código linguístico), disponibilizados aos usuários das informações. A compreensão dos usuários implica que os signos que compõem a mensagem sejam decodificados (ILUFI, 2000).

A contabilidade, enquanto linguagem, pode ser percebida sob as abordagens sintática, semântica e pragmática (KAM, 1990). Essa tridimensionalidade da linguagem tem sua origem na semiótica. Morris (1976) explica que a semiótica oferece uma linguagem geral, a qual possibilita a compreensão das atividades humanas, aplicável também à contabilidade e seus signos. Segundo Etheridge (1991), a fim de melhor compreender o processo de comunicação das informações contábeis pode-se usar os conceitos da semiótica, os quais permitem avaliar com precisão as dimensões semântica, sintática e pragmática.

Cada um dos níveis da tridimensionalidade elucida diferentes facetas da linguagem contábil. A abordagem sintática se refere ao modo como as informações financeiras são apresentadas e comunicadas aos usuários, utilizando uma lógica estritamente contábil. Referese à lógica ou sintaxe da linguagem, às regras gramaticais, no caso das teorias verbais, ou às regras atemáticas, quando a teoria utiliza esse tipo de linguagem. A abordagem semântica 
focaliza a compreensão do significado das informações contábeis pelos seus usuários. Diz respeito ao relacionamento entre uma palavra, símbolo ou sinal e um objeto ou evento do mundo real. A abordagem pragmática situa-se na utilidade da informação contábil para a tomada de decisões e envolve o efeito das palavras e símbolos sobre as pessoas (KAM, 1990).

$\mathrm{Na}$ área contábil, a semiótica tem como finalidade subsidiar a compreensão sobre: (1) como as informações contábeis são apresentadas e comunicadas; (2) o significado das informações contábeis; e (3) a utilidade da informação contábil. Ainda que de forma não explícita, as abordagens da linguagem contábil estão presentes ao tentar explicar estas afirmações. Embora essas preocupações devam existir na comunicação com os usuários da contabilidade gerencial, elas são especialmente importantes quando se trata da comunicação com os usuários externos da contabilidade, já que o acesso desses às informações é mais restrito e se circunscreve ao que é publicado pelas empresas.

Gaffikin (2006, p. 13) ressalta que "o conhecimento só pode existir por meio da comunicação e a linguagem é o meio de comunicação mais comum”. Esse autor destaca ainda que, por meio da linguagem a contabilidade é construída e constrói uma realidade. Portanto, a análise da tridimensionalidade da linguagem nas publicações em periódicos de contabilidade apresenta-se como uma lacuna de pesquisa a ser explorada. Assim, a questão de pesquisa que orienta este estudo é: Quais abordagens da linguagem contábil foram adotadas na sustentação teórica das publicações em periódicos científicos no período 2001-2012, relativas à Contabilidade para Usuários Externos e a Mercados Financeiro, de Crédito e de Capitais? Assim, o estudo objetiva investigar a linguagem contábil adotada na sustentação teórica de publicações em periódicos científicos brasileiros no período 2001-2012, relativas à Contabilidade para Usuários Externos e a Mercados Financeiro, de Crédito e de Capitais.

A relevância do estudo está em verificar se as pesquisas em contabilidade evoluíram desde 1990, já que Kam (1990) afirmava naquela época que o campo contábil se contentava com relacionamentos de natureza semântica vagos, e que muitos conceitos de origem sintática careciam de conteúdo semântico. Todavia, esse autor ressalta que, embora precisem ser incentivadas, as pesquisas com orientação semântica são complexas e oferecem dificuldades para a sua realização. O estudo contribui também por permitir conhecer as abordagens teóricas preconizadas nos artigos científicos desenvolvidos pelos pesquisadores da área de contabilidade, em particular sobre Contabilidade para Usuários Externos e Mercados Financeiro, de Crédito e de Capitais.

Cardoso et al. (2005, p. 35) mencionam que mapear e conhecer trabalhos acadêmicos publicados em determinada área por meio de revisões sistemáticas é uma das formas de possibilitar a avaliação e a reflexão desses trabalhos e da área em questão. Ressalta-se que não há no Brasil estudos com enfoque direcionado à caracterização de pesquisas sobre a abordagem da linguagem contábil, e este, por ser pioneiro ao tema, contribuirá de forma a instigar a academia brasileira a olhar as pesquisas quanto à tridimensionalidade da linguagem.

Esta pesquisa justifica-se pela relevância de mostrar uma análise crítica da produção científica, buscando contribuir para a sua melhoria. A contribuição da pesquisa evidencia-se na medida em que revela as tendências de investigações na temática da Contabilidade, em específico das áreas focalizadas na análise, quanto ao tipo de abordagem da linguagem utilizada no desenvolvimento dos estudos, propondo uma metodologia que permita classificar os estudos de modo a evidenciar o tipo de abordagem.

\section{TRIDIMENSIONALIDADE DA LINGUAGEM CONTÁBIL}

A tridimensionalidade da linguagem contábil tem suas origens na semiótica, a qual examina os modos de constituição dos fenômenos de produção, significação e sentido (SANTAELLA 1998). A semiótica fundamenta qualquer ciência que utiliza signos para sua comunicação, como a linguística, a lógica, a matemática e a retórica (MORRIS, 1976). Nesse 
sentido, os homens desenvolveram linguagens especificas e restritas, a fim de melhor alcançarem certos objetivos (MORRIS, 1976). Nesta perspectiva que a contabilidade é vista como uma linguagem de negócios (LAVOIE, 1987; ILUFI, 2000; KILLIAN, 2010).

Portanto, na perspectiva contábil, a semiótica contribui com a representação a partir de números e palavras para uma melhor compreensão das informações de natureza econômica e eventos contábeis (NAKAGAWA; DIAS FILHO, 2002). Para Etheridge (1991), os conceitos de semiótica permitem a compreensão do processo de comunicação das informações contábeis, podendo ser utilizada como instrumento de apoio à avaliação da tridimensionalidade da linguagem contábil. Na Figura 1 é apresentada a tridimensionalidade da linguagem contábil, com ênfase nas categorias e subcategorias que a compõem.

Figura 1 - Tridimensionalidade da linguagem contábil

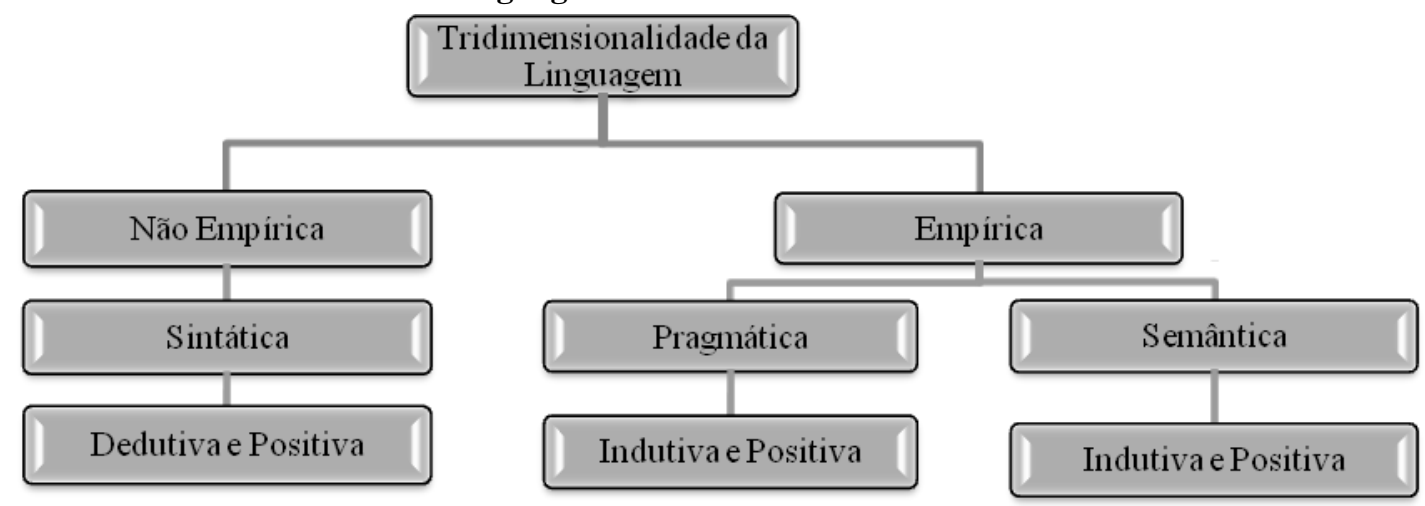

Fonte: Elaboração própria.

As pesquisas com abordagem sintática caracterizam-se por serem pesquisas não empíricas, e as pesquisas nas dimensões semânticas e pragmáticas são classificadas como pesquisas empíricas. As ciências empíricas estudam objetos concretos e dependem de testes experimentais, baseiam-se na experiência e observação (HENDRIKSEN; VAN BREDA, 2011). Em contraponto, os estudos não empíricos estudam "os objetos abstratos, cujos argumentos e teoremas dispensam testes para experimentação" (MARTINS; THEÓPHILO, 2009, p. 39), ou seja, se utilizam somente da lógica e da matemática para descrever os fenômenos observados.

De acordo com Martins e Theóphilo (2009, p, 39), o empirismo "explica apenas a face observável da realidade, ou a superfície dos fenômenos". Morris (1976, p. 16) expõe que a sintaxe, "enquanto estudo das relações sintáticas dos signos, é a parte mais desenvolvida de todos os ramos da semiótica". O autor frisa que "não é possível ter uma língua se o conjunto de signos não tiver dimensão sintática".

A sintaxe, segundo Blikstein (1973) e Morris (1976), é a parte da gramática que descreve as regras pelas quais se combinam as unidades significativas em frases, e estuda as propriedades formais das construções linguísticas. Ferreira (1986) e Lillo-Martin (2006) afirmam que a sintática é a parte da gramática que estuda a disposição das palavras na frase e das frases no discurso, bem como a relação entre si e a correta construção gramatical. Exemplificando, se a teoria em estudo é expressa em Inglês, então essa relação se refere às regras gramaticais da lingua Inglesa. Do mesmo modo, se a base teórica é fundamentada na matemática, então essa relação refere-se às regras da matemática. Portanto, a sintaxe lida com as formas e estruturas de dados e preocupa-se com a forma física e não o conteúdo dos dados.

Hendriksen e Van Breda (2011, p. 29) aduzem que a abordagem sintática compreende "o estudo da lógica ou gramática da linguagem". Nesta perspectiva salientam que os estudos contábeis que se utilizam da sintática não podem ser confirmados por causa de observações 
empíricas, mas sim por causa das regras convencionais da contabilidade. Isto é, demonstram e explicam por meio de estudo descritivo quais e como as informações financeiras são apresentadas e comunicadas aos usuários, utilizando-se apenas da lógica.

A lógica, conforme Ijiri (1975), pode se referir à estrutura total do raciocínio dedutivo ou simplesmente para a razoabilidade do argumento. A lógica não possui relação com o conteúdo empírico das regras presentes na contabilidade. Porém, colabora na organização das regras, devido ao grau de generalidade que se pode obter em suas aplicações. Hendriksen e Van Breda (2011) entendem que pesquisas voltadas ao enfoque estrutural da contabilidade identificam-se com a orientação sintática.

Dias Filho (2009) explica que ao nível sintático, a compreensão das informações contábeis se dá à luz do conjunto de normas e princípios que regem a sua produção. Nessa concepção, a finalidade da análise sintática é verificar se as informações contábeis obedecem a um conjunto de regras significativas, de modo que o usuário das demonstrações contábeis possa compreender o seu sentido e suas limitações. Por exemplo, o valor atribuído ao que se denomina "lucro" na contabilidade provém da subtração de receitas e despesas. No entanto, a base utilizada para a mensuração de receitas e despesas pode altera-lo.

Em relação à finalidade da análise, a mesma pode ser explicada a partir de duas variáveis. A primeira ocorre em relação à mensuração e vinculação, cuja base se dá em um enfoque mais tradicional da contabilidade, consistindo na elaboração da demonstração de resultado tradicional, com foco na receita e despesa. A segunda ocorre em relação à mensuração e crescimento natural, sendo que o enfoque deixa de ser a receita e despesa e passa a ser o ativo e o passivo (HENDRIKSEN; VAN BREDA, 2011).

Diante dos aspectos mencionados, é possível considerar que os estudos em contabilidade com foco principal na dimensão sintática são relevantes na construção do conhecimento. Estudos contábeis com abordagem sintática trazem à tona informações importantes acerca de conceitos, regras e normas presentes na contabilidade. Ainda esclarecem e explicam termos e procedimentos usados na contabilidade, de modo a facilitar a compreensão do usuário.

A segunda dimensão, a abordagem semântica, por sua vez, trata das relações entre supostos sinais e o que eles significam (STAMPER, 1985). A semântica atribui significado aos dados do nível sintático, ou seja, refere-se ao estudo dos significados da linguagem. No caso da contabilidade, consiste em encontrar maneiras de melhorar a interpretação das informações contábeis em termos da observação e da experiência humana (HENDRIKSEN; VAN BREDA, 2011).

A semântica atém-se à relação de significados dos signos e à representação do sentido dos enunciados (FERREIRA, 1986). É a área coberta no domínio da significação, por uma palavra ou por um grupo de palavras da língua. O nível semântico analisa a relação entre as unidades linguísticas do mundo (BLIKSTEIN, 1973). Na contabilidade, o foco do estudo é semântico quando se pretende descrever, explicar ou predizer a natureza dos objetos ou eventos contábeis (COLAUTO, 2005).

De acordo com Dias Filho e Nakagawa (2001), num processo de comunicação, o problema semântico diz respeito à distância existente entre o significado que um emissor pretende transmitir por meio de determinado código e a interpretação que o receptor atribui à mensagem recebida. Nesse aspecto, na área contábil, a dificuldade de ordem semântica se manifesta quando o significado que o contador pretende atribuir para termos e expressões veiculados nas demonstrações contábeis se distancia daquele que realmente lhes é atribuído pelos respectivos destinatários. Werner (1994) adverte que essa distância pode ser maior quando os indivíduos falam diferentes idiomas, em virtude das diferentes visões de mundo.

As dimensões que operam ao nível semântico se associam às informações ao invés de dados. A semântica está preocupada com o significado. Trata-se da interpretação de dados 
Josilene da Silva Barbosa - Luciana Klein - Romualdo Douglas Colauto - Ilse Maria Beuren

para obter o significado de comunicação. As dimensões de qualidade de dados da literatura de pesquisa operando no nível semântico incluem ambiguidade, credibilidade, interpretabilidade, confiabilidade significativa, compreensibilidade, validade, conteúdo, informatividade (TEJAY; DHILLON; CHIN, 2006).

Portanto, a semântica diz respeito a uma palavra, símbolo ou sinal atribuído para um objeto ou evento do mundo real. Morris (1976, p. 26) afirma que "um signo tem uma dimensão semântica na medida em que há regras semânticas (se formuladas ou não, é irrelevante) que determinam a sua aplicabilidade a certas situações sob certas condições". São as relações semânticas que fazem uma teoria ser realista e significativa. No campo semântico é preciso considerar que o valor das informações depende da capacidade que elas têm de melhorar o conhecimento sobre uma determinada realidade, ajudando a reduzir possíveis riscos e incertezas, de tal maneira que os usuários sintam-se mais tranquilos e apoiados no processo decisório (KAM, 1990).

A dimensão semântica se dá na relação entre o signo e seu significado, por exemplo, ativos disponíveis são os recursos que estão em condições de serem usados imediatamente, um deles, seriam os fundos depositados em conta corrente (ILUFI, 2000). Dias Filho (2009) aponta que a abordagem semântica busca verificar a fidelidade da representação, isto é, se existe correspondência entre as descrições alfanuméricas que integram as demonstrações contábeis e os atributos dos eventos que elas buscam representar.

Por isso, sob o ponto de vista da semiótica, é importante avaliar se os termos empregados na evidenciação contábil despertam os significados pretendidos pelos produtores das informações. A falta de definições claras e suficientes dos termos utilizados pela contabilidade, segundo Costa e Theóphilo (2000), é a principal dificuldade com a utilização do enfoque semântico. Conceitos como ativo, passivo, receitas e despesas, por exemplo, não possuem um conteúdo semântico definido e aceito de forma ampla.

Theóphilo (2000) afirma que mesmo os conceitos contábeis necessitando de definições mais claras, os trabalhos que se propõem ao estudo dos significados da linguagem são bastante raros e pertencem, em sua maior parte, às abordagens sobre Teoria da Contabilidade. $\mathrm{O}$ autor esclarece que, embora precisem ser incentivadas, as pesquisas com orientação semântica são complexas e oferecem dificuldades para sua realização. Desse modo, a busca por uma maior aproximação com o campo de estudos da semiótica é um importante esforço na intensificação das investigações dessa natureza.

A terceira dimensão, a abordagem pragmática, "tem os seus aspectos puros e descritivos" (MORRIS, 1976, p. 24). Ela diz respeito às características de sua utilização, ou seja, motivações psicológicas dos falantes, reações dos interlocutores, tipos socializados da fala, objetos da fala. É o ramo da semiologia que se interessa especificamente pela relação entre o signo e o usuário deste signo (BLIKSTEIN, 1973). A linguagem pragmática fundamenta a ideia que se tem de um objeto qualquer. Nada mais se não a soma das ideias de todos os efeitos imagináveis atribuídos a esse objeto, que possam ter um efeito prático qualquer (FERREIRA, 1986).

A abordagem pragmática está preocupada com as relações entre os sinais e o comportamento em um determinado contexto. A abordagem pragmática trata do uso das informações por pessoas. Ela está preocupada com a relação entre dados, informações e comportamento, em um dado contexto. As dimensões de qualidade de dados da literatura de pesquisa quanto ao nível pragmático incluem adequação, relevância, valor acrescentado, suficiência, importância, utilidade e reputação (TEJAY; DHILLON; CHIN, 2006).

Em 1962, Bedford e Beladouni já afirmavam que a comunicação contábil pode sofrer prejuízos na fase de produção de seus relatórios, caso o profissional contábil não interprete e codifique adequadamente os fenômenos econômicos que pretende demonstrar (COLAUTO; BEUREN; MEDINA, 2005). Pode-se argumentar que a compreensibilidade das informações 
depende também de outros atributos qualitativos, como a pontualidade, uniformidade e adequação dos dados aos modelos decisórios. Portanto, caso a informação transmitida seja incompreensível, significa que o esforço de produzi-la foi inválido. Em tal circunstância, os dados não chegam ao status de informações, mas acabam por tornarem-se um conjunto de dados desprovidos de valores semânticos (COLAUTO; BEUREN; MEDINA, 2005).

Hendriksen e Van Breda (2011) aduzem que a linguagem pragmática estuda o efeito da linguagem, preocupa-se com a importância e utilidade das informações nas decisões, ajudando nas predições de resultados e no entendimento de eventos presentes e passados. Para Kam (1990), nesta abordagem a contabilidade está preocupada em conhecer como os conceitos contábeis e suas medidas correlatas no mundo real colidem no comportamento humano. "A dimensão pragmática se dá na relação dos signos com seus intérpretes" (MORRIS, 1976, p. 50). Ilufi (2000) cita como exemplo, que contadores e gerentes consideram "ativos disponíveis" de formas diferentes. Para o primeiro, ativos disponíveis são considerados os ativos mais líquidos da empresa, já os gerentes os consideram como a possibilidade de realizar investimentos ou quitar dívidas.

Para Dias Filho (2009), verificar o grau de adequação das informações contábeis aos objetivos de seus destinatários é o objetivo da abordagem pragmática. Além disso, é preciso considerar que a informação contábil deve ser suficientemente relevante para melhorar a qualidade das decisões de seus usuários. Isto significa que deve haver compatibilidade em grau satisfatório entre o conteúdo dos relatórios contábeis e os objetivos de seus destinatários, ou seja, é necessário fornecer informações pertinentes, porque não acrescenta em nada fornecer informações que não sejam capazes de melhorar o poder de decisão do gestor.

Dentre os três níveis representativos da linguagem, a Teoria Contábil tem maior identificação com a orientação pragmática. Segundo Kam (1990), isso se deve à própria natureza da Contabilidade e ao seu objetivo de satisfazer necessidades informativas dos usuários. Hendriksen e Van Breda (2011) destacam que os enfoques econômico e comportamental da contabilidade apresentam estilo pragmático. Ademais, nota-se que a abordagem pragmática desempenha papel importante no que tange às necessidades do usuário da informação. Pois, seu foco principal está no atendimento das prioridades e necessidades do usuário, ou seja, a informação deve acima de tudo ter relevância e utilidade aos usuários.

Nesse contexto, o estudo de Colauto, Beuren e Medina (2005) se propôs a fazer uma incursão teórica do processo de mensuração dos ativos intangíveis, em particular o capital intelectual, sob o enfoque da tridimensionalidade da linguagem contábil. Os resultados do estudo sugerem que os ativos possuem diferentes atributos de mensuração e que para os usuários da informação é relevante que seja considerado mais de um atributo na mensuração dos ativos. Ainda, Colauto e Beuren (2005) estudaram os indicadores considerados pioneiros na mensuração do ativo intangível elaborados por Leif Edvinsson e Michael S. Malone, Thomas A. Stewart e Karl Erik Sveiby, em que abordaram a avaliação do capital intelectual na perspectiva da tridimensionalidade da linguagem contábil, sendo que os resultados do estudo mostram que os indicadores, de maneira geral, tentam identificar como as ações empregadas nas empresas influenciam o valor dos ativos.

O Financial Accounting Standards Board (FASB) (1980), no SFAC n ${ }^{\circ}$, destaca a importância da utilidade e relevância da informação contábil, de modo que sua maior preocupação quanto à teoria como linguagem está na abordagem pragmática. Vale citar que o mesmo não deixa de considerar a importância dos objetivos, quanto aos focos sintáticos e semânticos. Dias Filho (2000, p. 47) explica que "a eficácia de uma mensagem é medida pela quantidade de informações assimilada e pelo volume de alternativas que ela permite ao usuário descartar". Ou seja, a informação deve ser útil, de modo que as dúvidas e as incertezas sejam sanadas, ou pelo menos reduzidas. Nesse sentido, cada uma das dimensões possui propósitos específicos e interage de forma concomitante, formando esta tridimensionalidade 
de relações (COLAUTO, 2005).

\section{PROCEDIMENTOS METODOLÓGICOS DA PESQUISA}

Para a consecução do objetivo desta pesquisa buscou-se mapear as abordagens da linguagem contábil preconizadas na sustentação teórica de publicações relativas às temáticas de Contabilidade para Usuários Externos e de Mercados Financeiro, de Crédito e de Capitais. A presente pesquisa se classifica como descritiva e foi realizada com abordagem empíricoanalítica, conduzida pela técnica da Análise de Conteúdo.

\subsection{Definição da população e amostra da pesquisa}

Foram investigados os artigos publicados no período 2001 a 2012 em periódicos nacionais da área Contábil classificados nos Estratos A2, B1 e B2 do Qualis CAPES, da Coordenação de Aperfeiçoamento de Pessoal de Nível Superior.

Os artigos foram levantados nos respectivos sítios de cada periódico, no período entre outubro e novembro de 2013 totalizando 1.284 artigos. Destes, foram selecionados os 313 artigos que investigaram conteúdos relativos às temáticas de Contabilidade para Usuários Externos e de Mercados Financeiro, de Crédito e de Capitais. Os artigos foram lidos pelos pesquisadores a fim de identificar o tipo de linguagem contábil empregado na construção da fundamentação teórica.

Na classificação dos artigos foi adotado como parâmetro a divisão temática utilizada pela Revista Contabilidade \& Finanças, USP, por ser este o periódico precursor das publicações em contabilidade no Brasil e constar em estrato superior (A2) do Qualis CAPES. No Quadro 1 apresentam-se as divisões e focos temáticos utilizados na pesquisa.

Quadro 1 - Divisão temática para classificação do foco das publicações

\begin{tabular}{|c|c|c|}
\hline Divisões temáticas & Focos Temáticos & Abreviações \\
\hline \multirow{11}{*}{ Usuários Externos } & Teoria da Contabilidade & $\mathrm{TC}$ \\
\hline & Contabilidade Societária & $\mathrm{CS}$ \\
\hline & Convergência de Normas & $\mathrm{CN}$ \\
\hline & Balanço Social (DVA, MA, RH) & BS \\
\hline & Capital Intelectual & $\mathrm{CI}$ \\
\hline & Contabilidade Pública e de Terceiro Setor & $\mathrm{CP} / \mathrm{TS}$ \\
\hline & Auditoria Independente & $\mathrm{AI}$ \\
\hline & Análise das Demonstrações Contábeis & $\mathrm{ADC}$ \\
\hline & Reconhecimento dos Efeitos Inflacionários & REI \\
\hline & Contabilidade Tributária & CT \\
\hline & Governança Corporativa & GC \\
\hline \multirow{6}{*}{$\begin{array}{l}\text { Mercados Financeiro, } \\
\text { de Crédito e de } \\
\text { Capitais }\end{array}$} & Auditoria & $\mathrm{A}$ \\
\hline & Finanças Corporativas CP/LP & $\mathrm{FC}$ \\
\hline & Valuation & $\mathrm{V}$ \\
\hline & Gestão de Riscos & GR \\
\hline & Métodos Quantitativos Aplicados à Contabilidade Societária & MQ \\
\hline & Finanças Pessoais & FP \\
\hline
\end{tabular}

Fonte: Elaborado com base nos critérios utilizados na Revista Contabilidade \& Finanças, USP.

Ressalta-se que este critério de classificação dos periódicos em divisões temáticas e focos temáticos pode representar uma limitação desta pesquisa, já que outros periódicos possuem classificações próprias, apesar de não serem bem definidos. 


\subsection{Critérios de classificação dos artigos na tridimensionalidade da linguagem contábil}

Os critérios adotados para a classificação dos artigos quanto à tridimensionalidade da linguagem contábil foram fundamentados em Ijiri (1975), Kam (1990), Ilufi (2000), Dias Filho (2009) e Hendriksen e Van Breda (2011). No Quadro 2 apresenta-se o construto da pesquisa elaborado com base nessas referências.

Quadro 2 - Construto da pesquisa

\begin{tabular}{|c|c|c|c|}
\hline & Tipo & Variáveis operacionais & Definição constitutiva das variáveis \\
\hline & & Lógica & $\begin{array}{l}\text { Estudar a lógica das palavras, símbolos, números e a } \\
\text { gramática da linguagem. }\end{array}$ \\
\hline & & Compreensão & $\begin{array}{l}\text { Compreender as informações contábeis à luz do conjunto } \\
\text { de normas e princípios. }\end{array}$ \\
\hline & 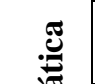 & Forma linguística & $\begin{array}{l}\text { Estudar as propriedades formais das construções } \\
\text { linguísticas. }\end{array}$ \\
\hline & 芦 & Divulgação de informações & $\begin{array}{l}\text { Demonstrar e explicar quais e como as informações } \\
\text { financeiras são apresentadas e comunicadas aos usuários } \\
\text { (lógica). }\end{array}$ \\
\hline & & Relação lógica entre dados contábeis & Verificar se um dado está logicamente relacionado a outro. \\
\hline & & Regras, normas, leis e princípios. & $\begin{array}{l}\text { Confirmar os estudos pelas regras convencionais da } \\
\text { contabilidade. }\end{array}$ \\
\hline & & Percepção sobre temas & Estudar a percepção do indivíduo. \\
\hline & & Redução de riscos e incertezas & Ajudar a reduzir possíveis riscos e incertezas. \\
\hline & & Fidelidade & Verificar a fidelidade da representação da informação. \\
\hline 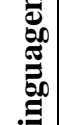 & & Representação & $\begin{array}{l}\text { Verificar se há correspondência entre as descrições } \\
\text { alfanuméricas (demonstrações contábeis) e os atributos dos } \\
\text { eventos que elas buscam representar. }\end{array}$ \\
\hline$\sqrt{3}$ & త్ & Relações linguísticas & Analisar a relação entre as unidades linguísticas do mundo. \\
\hline 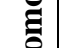 & 吾 & Tomada de decisão & Apoiar o processo decisório. \\
\hline 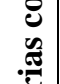 & हूँ & Descrição, explicação ou predição & $\begin{array}{l}\text { Descrever, explicar, ou predizer a natureza dos objetos ou } \\
\text { eventos Contábeis. }\end{array}$ \\
\hline$\stackrel{\vec{d}}{\stackrel{\theta}{*}}$ & & Interpretação & $\begin{array}{l}\text { Buscar melhorar a interpretação das informações contábeis } \\
\text { em termos da observação e da experiência humana. }\end{array}$ \\
\hline & & Compreensão & $\begin{array}{l}\text { Constatar se o usuário da informação contábil está } \\
\text { compreendendo o significado das informações contábeis. }\end{array}$ \\
\hline & & Significado do signo & $\begin{array}{l}\text { Verificar o significado da palavra, símbolos ou números } \\
\text { para os usuários. }\end{array}$ \\
\hline & & Fundamentação & Fundamentar a ideia que se tem de um objeto qualquer. \\
\hline & & Soma de ideias & $\begin{array}{l}\text { Somar as idéias de todos os efeitos imagináveis atribuídos } \\
\text { a um objeto. }\end{array}$ \\
\hline & 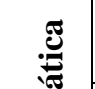 & Efeito da linguagem & $\begin{array}{l}\text { Estudar o efeito da linguagem (palavras, números ou } \\
\text { símbolos) nos usuários. }\end{array}$ \\
\hline & 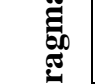 & Predição e compreensão & $\begin{array}{l}\text { Ajudar na predição de resultados e no entendimento de } \\
\text { eventos presentes e passados. }\end{array}$ \\
\hline & A & Adequação & $\begin{array}{l}\text { Verificar o grau de adequação das informações contábeis } \\
\text { aos objetivos de seus destinatários. }\end{array}$ \\
\hline & & Utilidade e relevância & $\begin{array}{l}\text { Focar na utilidade e relevância da contabilidade aos seus } \\
\text { usuários em relação à tomada de decisão. }\end{array}$ \\
\hline
\end{tabular}

Fonte: Elaborado com base em Ijiri (1975); Kam (1990); Ilufi (2000); Dias Filho (2009); Hendriksen e Van Breda (2011)

Em termos operacionais, a abordagem sintática refere-se à apresentação e explicação lógica da linguagem contábil e como um dado está relacionado ao outro por meio de regras ou convenções. A semântica relaciona-se ao significado da linguagem contábil para o usuário e se as informações financeiras são por ele compreendidas. A abordagem pragmática refere-se ao efeito da linguagem sobre o usuário nos aspectos comportamentais e econômicos. De 
forma geral, as diferenças nas características das abordagens da teoria como linguagem são bastante tênues: quanto à linguagem sintática, o foco principal está no produtor das informações e como estas são produzidas; na semântica e pragmática, o foco está na relevância da informação e na compreensão do usuário da informação.

Para a classificação dos artigos segundo a tridimensionalidade da linguagem contábil, nas abordagens semântica, pragmática e sintática, utilizou-se como critério operacional a análise crítica do conteúdo, conforme preconizado por Bardin (2004). Para tanto, foi realizada a leitura do título dos artigos, das palavras-chave, do resumo e do referencial teórico, nesta sequência, buscando identificar as variáveis (expostas no Quadro 2) que caracterizam cada abordagem. Em seguida, procedeu-se à quantificação das categorias identificadas.

\subsection{Limitações da pesquisa}

Como principal limitação metodológica da classificação dos artigos quanto à linguagem adotada, está a subjetividade da análise. Como forma de atenuar este subjetivismo na análise dos dados, foram adotados os seguintes procedimentos: a) leitura individual por parte de cada autor; b) discussão das dúvidas pendentes entre os autores; e c) leitura conjunta entre os autores; e, d) decisão sobre a classificação para os casos identificados na fronteira de dois tipos de linguagem.

Embora se reconheça que a subjetividade esteja refletida nos resultados da pesquisa, vale destacar que o ponto primordial da contribuição deste estudo está na tentativa de propor uma base metodológica que permita identificar e caracterizar as pesquisas quanto ao tipo de abordagem da linguagem contábil.

\section{DESCRIÇÃO E ANÁLISE DOS RESULTADOS}

\subsection{Características da população e amostra}

A população da pesquisa constitui-se de artigos publicados no período 2001 a $2012 \mathrm{em}$ periódicos nacionais da área Contábil classificados nos Estratos A2, B1 e B2 do Qualis CAPES, conforme Tabela 1. No ano de 2012 consideraram-se somente os artigos publicados nas duas primeiras edições em função da coleta de dados ter ocorrido em outubro de 2012.

Tabela 1 - Composição da população

\begin{tabular}{|c|c|c|c|c|c|}
\hline \multirow[b]{2}{*}{ Periódicos } & \multirow{2}{*}{$\begin{array}{c}\text { Estratos } \\
\text { Qualis } \\
\text { CAPES }\end{array}$} & \multirow{2}{*}{$\begin{array}{c}\text { Período de } \\
\text { coleta }\end{array}$} & \multirow{2}{*}{$\begin{array}{l}\text { Edições } \\
\text { coletadas }\end{array}$} & \multicolumn{2}{|c|}{ Artigos coletados } \\
\hline & & & & Quant. & $\%$ \\
\hline Revista Contabilidade \& Finanças- RC\&F & $\mathrm{A} 2$ & $2001-2012$ & 39 & 275 & 21,4 \\
\hline Brazilian Business Review - BBR & A2 & $2004-2012$ & 24 & 141 & 11,0 \\
\hline Contabilidade Vista \& Revista - CV\&R & B1 & $2001-2012$ & 39 & 241 & 18,8 \\
\hline Revista Universo Contábil - RUC & B1 & $2005-2012$ & 27 & 217 & 16,9 \\
\hline Revista de Contabilidade e Organizações - RCO & B1 & $2007-2012$ & 15 & 123 & 9,6 \\
\hline Contabilidade, Gestão e Governança - CGC & $\mathrm{B} 2$ & $2001-2012$ & 27 & 172 & 13,4 \\
\hline Enfoque: Reflexão Contábil - ERC & $\mathrm{B} 2$ & $2005-2012$ & 20 & 115 & 9,0 \\
\hline \multicolumn{4}{|c|}{ Totais } & 1284 & 100 \\
\hline
\end{tabular}

Fonte: Dados da pesquisa.

Observa-se na Tabela 1 que a Revista Contabilidade \& Finanças e a Contabilidade Vista \& Revista foram os periódicos que apresentaram o maior número de publicações no período analisado. Este último possui um total de 241 artigos, os quais foram publicados desde 2001 até a edição de número 3 de 2011, ou seja, este foi o único periódico não atualizado em outubro/2012, já que naquela data não havia publicado a última edição de 2011 e as edições de 2012.

A classificação dos estudos por focos temáticos permite verificar em quais estão 

CIENTIIFICOS BRASILEIROS

concentradas as diferentes abordagens da linguagem contábil. Ressalta-se, no entanto, a dificuldade que se teve em identificar as áreas e focos temáticos de alguns periódicos, devido ao fato de não explicitarem claramente isso em sua política editorial. Na Tabela 2 apresenta-se a composição da população considerando todas as divisões temáticas identificadas nos periódicos pesquisados.

Tabela 2 - Caracterização da população quanto à divisão temática

\begin{tabular}{l|c|c|c|c|c|c|c|c}
\hline \multicolumn{1}{c|}{ Divisões Temáticas } & \multicolumn{7}{c}{ Periódicos / Número de artigos } \\
\cline { 2 - 10 } & ERC & RC\&F & RUC & BBR & CV\&R & CGG & RCO & $\begin{array}{c}\text { Total } \\
\text { (n) }\end{array}$ \\
\hline Controladoria e Contabilidade Gerencial & 44 & 63 & 76 & 46 & 91 & 68 & 37 & 425 \\
\hline Contabilidade para Usuários Externos & 24 & 71 & 67 & 20 & 54 & 40 & 37 & 313 \\
\hline Mercados Financeiro, de Crédito e de Capitais & 17 & 98 & 37 & 46 & 34 & 36 & 25 & 293 \\
\hline $\begin{array}{l}\text { Educação e Pesquisa em: Contabilidade, } \\
\text { Controladoria, Atuária e Finanças }\end{array}$ & 30 & 41 & 37 & 17 & 58 & 24 & 22 & 229 \\
\hline Atuária & & 1 & & 4 & 1 & 1 & & 7 \\
\hline Administração & & & & 4 & 2 & & & 6 \\
\hline Economia & & & & 1 & 1 & 1 & 1 & 4 \\
\hline Marketing & & 1 & & 2 & & 1 & & 4 \\
\hline Analise de crédito & & & & & & 1 & 1 & 2 \\
\hline Sem classificação & 115 & 275 & 217 & 141 & 241 & 172 & 123 & 1.284 \\
\hline Total (n)
\end{tabular}

Fonte: Dados da pesquisa.

Nota-se na Tabela 2 que alguns periódicos publicaram artigos relacionados à Administração, Economia, Marketing e Análise de Crédito. Estes e mais dois artigos sem classificação quanto à divisão temática foram excluídos da amostra. Os últimos foram publicados no periódico Contabilidade, Gestão e Governança e Revista de Contabilidade e Organização. Denota-se que do total de artigos coletados, 425 referem-se à Controladoria e Contabilidade Gerencial, o que representa $33,1 \%$ da população. A maior parte dos artigos dessa temática foi publicada nos periódicos (1) Contabilidade Vista \& Revista; (2) Revista Universo Contábil; e (3) Contabilidade, Gestão e Governança. Na área de Educação e Pesquisa foram encontrados 229 artigos, destacando-se os periódicos Contabilidade Vista \& Revista e Revista Universo Contábil.

Como forma de delimitação amostral, permaneceram no estudo 313 artigos relacionados à área Contabilidade para Usuários Externos e 293 artigos na temática Mercados Financeiro, de Crédito e de Capitais. Portanto, a amostra da pesquisa totaliza 606 artigos publicados no período 2001-2012, conforme evidenciado nas Tabelas 3 e 4.

Tabela 3 - Caracterização da amostra da área de Contabilidade para Usuários Externos

\begin{tabular}{c|c|c|c|c|c|c|c|c}
\hline Anos & ERC & RC\&F & RUC & BBR & CV\&R & CGG & RCO & Totais (n) \\
\hline 2001 & & 6 & & & 2 & 1 & & 9 \\
\hline 2002 & & 4 & & & 4 & 2 & & 10 \\
\hline 2003 & & 13 & & & 7 & 2 & & 22 \\
\hline 2004 & & 8 & & 2 & 1 & 1 & & 12 \\
\hline 2005 & & 6 & 3 & 2 & 4 & 1 & & 16 \\
\hline 2006 & & 2 & 2 & 3 & 2 & 4 & & 13 \\
\hline 2007 & 5 & 9 & 5 & 1 & 4 & 2 & 2 & 28 \\
\hline 2008 & 5 & 5 & 14 & 2 & 6 & 11 & 6 & 49 \\
\hline 2009 & 4 & 5 & 11 & 5 & 9 & 6 & 8 & 48 \\
\hline 2010 & 4 & 5 & 16 & & 10 & 2 & 10 & 47 \\
\hline 2011 & 4 & 6 & 9 & 3 & 5 & 2 & 7 & 36 \\
\hline 2012 & 2 & 2 & 7 & 2 & & 6 & 4 & 23 \\
\hline Total & 24 & 72 & 67 & 20 & 54 & 40 & 37 & 313 \\
\hline
\end{tabular}

Fonte: Dados da pesquisa. 
Josilene da Silva Barbosa - Luciana Klein - Romualdo Douglas Colauto - Ilse Maria Beuren

Observa-se na Tabela 3 que a Revista Contabilidade \& Finanças possui maior representatividade na amostra, com 72 artigos publicados na área de Contabilidade para Usuários Externos. A Revista Universo Contábil foi a segunda maior em número de publicações nessa área, 67 artigos, representando 21,3\% da amostra. Na Tabela 4 apresentamse os artigos relacionados à área de Mercados Financeiro, de Crédito e de Capitais.

Tabela 4 - Classificação da amostra da área de Mercados Financeiro, de Crédito e de Capitais

\begin{tabular}{c|c|c|c|c|c|c|c|c}
\hline Anos & ERC & RC\&F & RUC & BBR & CV\&R & CGG & RCO & Totais (n) \\
\hline 2001 & & 2 & & & 4 & 6 & & 12 \\
\hline 2002 & & 4 & & & 2 & 2 & & 8 \\
\hline 2003 & & 9 & & & 2 & 1 & & 12 \\
\hline 2004 & & 10 & & 4 & 2 & 3 & & 19 \\
\hline 2005 & 1 & 11 & 1 & 2 & 1 & 2 & & 18 \\
\hline 2006 & 5 & 16 & 3 & 2 & 6 & 2 & & 34 \\
\hline 2007 & 2 & 10 & 2 & 6 & 3 & 6 & 2 & 31 \\
\hline 2008 & 1 & 9 & 4 & 11 & 4 & 3 & 7 & 39 \\
\hline 2009 & 5 & 10 & 11 & 7 & 5 & 3 & 5 & 46 \\
\hline 2010 & & 11 & 3 & 6 & 3 & 4 & 2 & 29 \\
\hline 2011 & 1 & 3 & 7 & 6 & 2 & 3 & 5 & 27 \\
\hline 2012 & 2 & 3 & 6 & 2 & & 1 & 4 & 18 \\
\hline Total & 17 & 98 & 37 & 46 & 34 & 36 & 24 & 293 \\
\hline
\end{tabular}

Fonte: Dados da pesquisa.

Verifica-se na Tabela 4, que dos artigos publicados na área de Mercados Financeiro, de Crédito e de Capitais, 98 foram na Revista Contabilidade \& Finanças. Mais uma vez esse periódico se sobressai em relação aos demais. Em seguida, com maior publicação aparece a revista Brazilian Business Review. A caracterização da temática dos artigos publicados tende a ser de interesse dos pesquisadores, já que no momento da escolha do periódico para submissão de um artigo, os mesmos podem tomar decisões mais assertivas se tiverem conhecimento do perfil dos artigos normalmente aceitos para publicação nos periódicos.

\subsection{Focos de publicação dos artigos nas áreas temáticas}

A partir da divisão temática para a classificação do foco das publicações apresentada no Quadro 1, realizou-se a classificação dos artigos na área temática Contabilidade para Usuários Externos. No Gráfico 1 evidenciam-se os três principais focos, que foram: (1) Teoria da Contabilidade, (2) Convergência de Normas e (3) Balanço Social.

Gráfico 1 - Principais focos de publicação na divisão temática Usuários Externos (valores relativos)

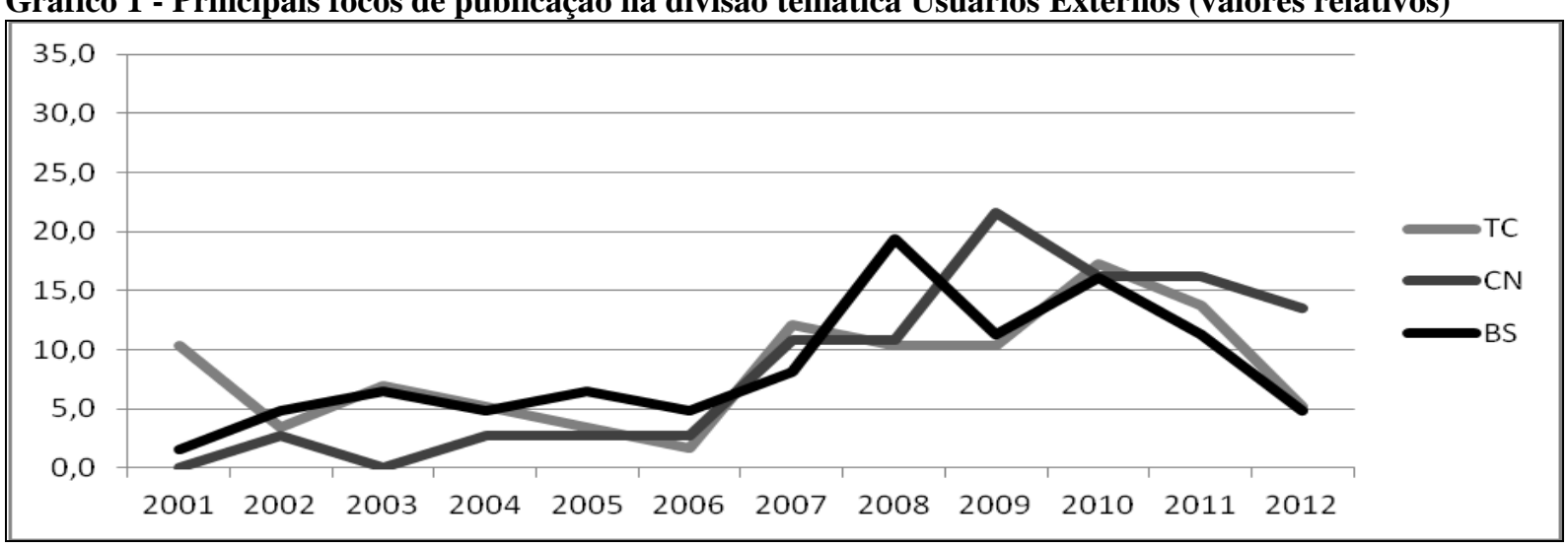

Fonte: Dados da pesquisa. 
As pesquisas em Teoria da Contabilidade, conforme demonstrado no Gráfico 1, apresentaram picos de produção em 2007 e 2010, representando $11 \%$ e $17 \%$ da produção total. As investigações sobre Convergência de Normas tiveram seu ponto alto em 2009, dobrando a sua representatividade de publicações. Em 2007 e 2008 representavam $11 \%$ das pesquisas neste foco, e em 2009 passaram para 21\%. Este fato pode ser justificado pela adesão do Brasil ao processo de convergência das normas contábeis, marcado especialmente pela reformulação da Lei n. 11.638/2007 e pela adoção obrigatória dos pronunciamentos contábeis (CPCs) já nas demonstrações contábeis publicadas no ano de 2010, conforme Deliberação CVM n 647 de 02.12.2010 e Deliberação CVM nº 651 de 16.12.2010.

Outro foco de grande representatividade refere-se ao Balanço Social, que neste caso engloba os textos relativos à Demonstração do Valor Adicionado, Meio Ambiente e Recursos Humanos. Tais estudos tiveram grande circulação em 2008, com 19\% das publicações. Isto pode ser um indício da preocupação da academia em acompanhar ações empresariais relacionadas a questões socioambientais. A maior parte dos artigos do grupo Balanço Social trata do disclosure de informações, que indireta ou diretamente estão inseridos no contexto da sustentabilidade. Portanto, estudos que lançavam seu olhar sobre a relação da contabilidade e a sustentabilidade tiveram maior ênfase neste período.

No Gráfico 2, apresentam-se os três focos temáticos que tiveram maior destaque na área de Mercados Financeiro, de Crédito e de Capitais. Destacaram-se os artigos relacionados a Finanças Corporativas de Curto e Longo Prazo, Gestão de Risco e Valuation.

Gráfico 2 - Principais focos de publicação na divisão temática Mercados Financeiro, de Crédito e de Capitais (valores relativos)

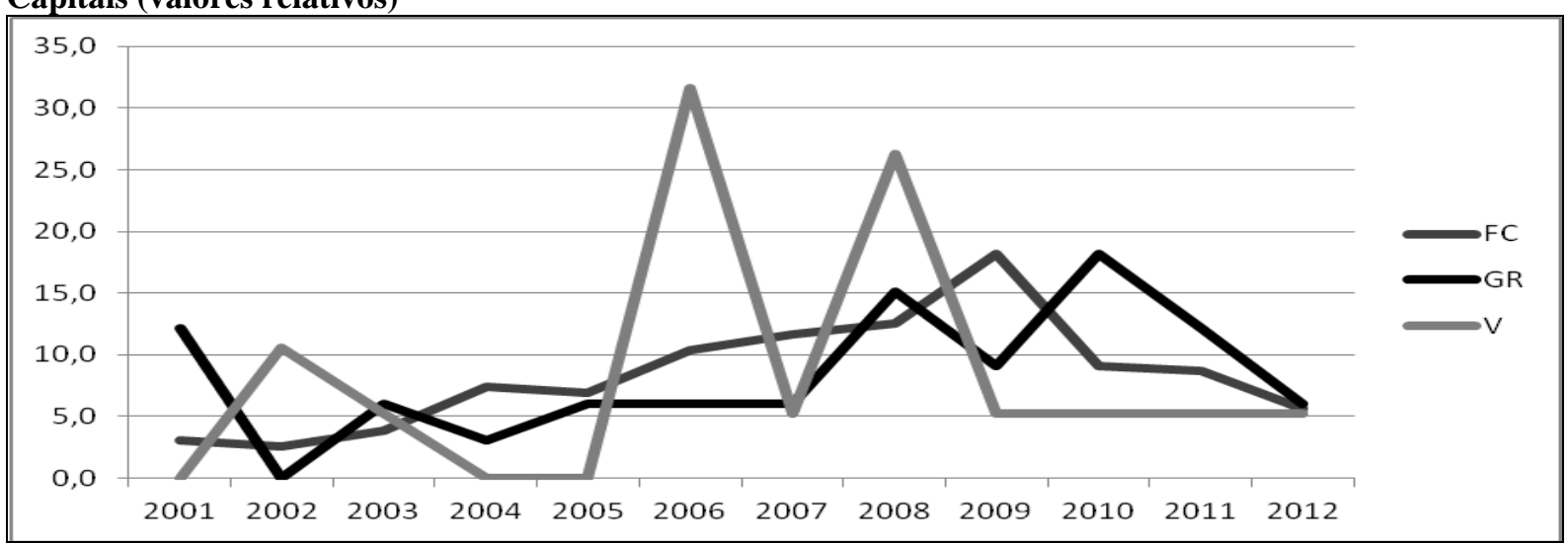

Fonte: Dados da pesquisa.

Pesquisas relacionadas a Finanças Corporativas, conforme demonstrado no Gráfico 2, obtiveram maior concentração em 2009 , com $18 \%$ das publicações; as pesquisas sobre Gestão de Risco tiveram maior incidência em 2008, com 15\%, e 2010, com 18\% das publicações. Tal incidência pode ser atribuída à crise econômica de 2008, que despertou interesse sobre os reflexos da crise no risco do negócio. É possível que a crise econômica também tenha favorecido as pesquisas sobre valoração dos ativos, que tiveram uma maior ascensão no período de 2006 e 2008 , com $32 \%$ e $26 \%$ nessa ordem.

\subsection{Classificação dos artigos quanto à Tridimensionalidade da Linguagem Contábil}

No Gráfico 3 apresenta-se a análise dos periódicos quanto a abordagem da Tridimensionalidade da Linguagem Contábil preconizada em suas publicações. 
Josilene da Silva Barbosa - Luciana Klein - Romualdo Douglas Colauto - Ilse Maria Beuren

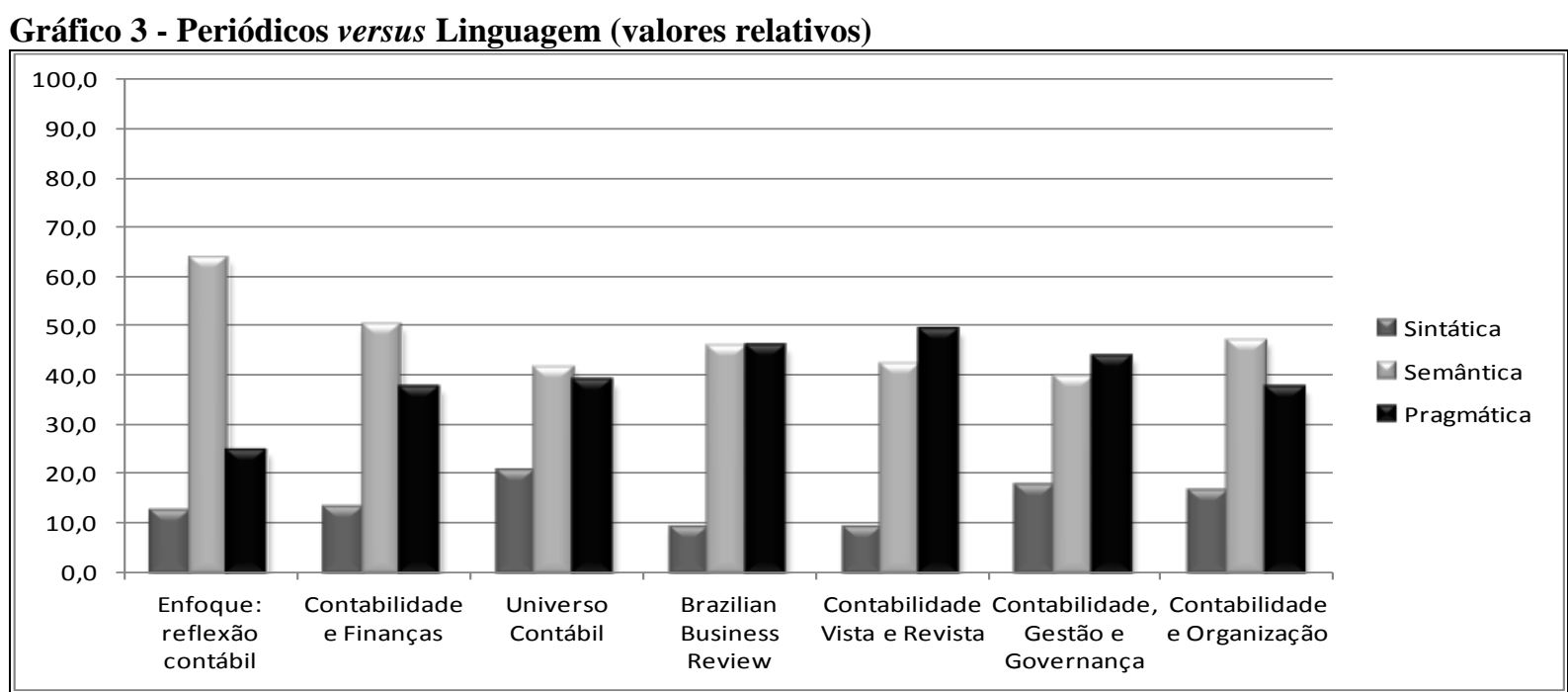

Fonte: Dados da pesquisa.

Observa-se no Gráfico 3, em termos quantitativos, que a abordagem semântica se sobressai às linguagens pragmática e sintática. A abordagem pragmática, por sua vez, se sobressai à sintática. Este resultado confronta com os achados de Theóphilo (2000), pois o autor observou que as pesquisas em contabilidade em sua maioria priorizam investigações de ordem pragmática. Já os trabalhos que se propõem ao estudo dos significados da linguagem semântica - são bastante raros. Talvez o período de análise distinto possa ter influenciado os resultados, bem como as diferenças nas bases de dados consideradas em ambos os estudos.

No Gráfico 4 buscou-se verificar se os artigos de cada divisão temática apresentam afinidade com uma das abordagens da linguagem contábil.

Gráfico 4 - Divisão temática versus Linguagem (valores relativos)

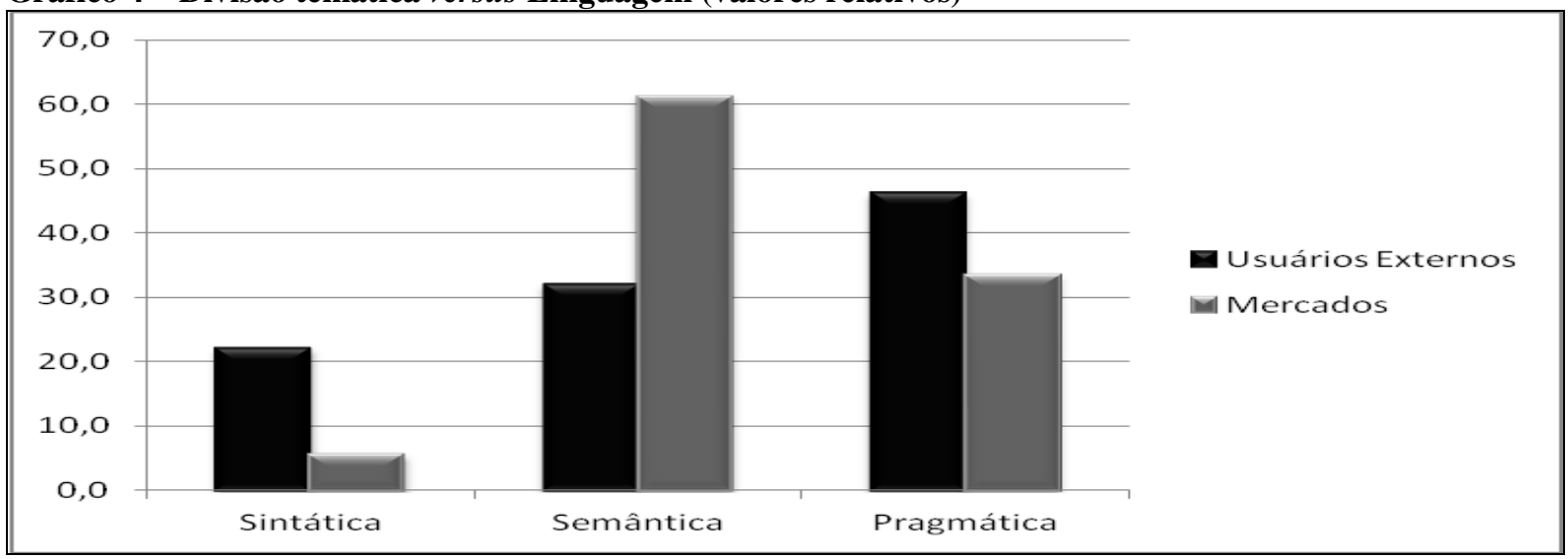

Fonte: Dados da pesquisa.

Verifica-se no Gráfico 4 que artigos voltados para assuntos relacionados a Contabilidade para Usuários Externos são mais propensos à utilizarem a abordagem pragmática, representando 46\% da amostra. Embora o FASB (1980) não rejeite os objetivos sintáticos e semânticos, este órgão regulador apresenta maior preocupação com o enfoque pragmático, direcionado à utilidade ou relevância da informação contábil para os investidores e outros usuários. Este fato pode ter também influenciado as pesquisas acadêmicas no Brasil, já que havia uma preocupação excessiva com aspectos normativos da contabilidade e fortemente concentrada na legislação norte-americana.

Diferentemente nos artigos que buscaram elucidar problemas voltados à área de 
Mercados Financeiro, de Crédito e de Capitais, que utilizaram-se principalmente da abordagem semântica, representando $61 \%$ da amostra. Essa temática busca relacionar o significado da linguagem para o usuário e se as informações são por eles compreendidas. Dias Filho (2000) ressalta que a eficácia de uma mensagem é medida pela quantidade de informações assimilada e pelo volume de alternativas que ela permite ao usuário descartar. A essência da informação está na redução das incertezas e dos riscos. Esta premissa guarda estreita relação com a capacidade de compreensão daquilo que se pretende transmitir.

Tais resultados estão condizentes com a teoria, pois, as pesquisas em Contabilidade para Usuários Externos se atêm principalmente às questões de divulgação de informações aos usuários, portanto, coincidindo com a proposta da abordagem pragmática da contabilidade. As pesquisas sobre a temática de Mercados Financeiro, de Crédito e de Capitais visam esclarecer possíveis riscos e incertezas na interpretação das informações contábeis, por meio da interpretação dos signos para a representação correta da mensagem, características essas proeminentes na abordagem semântica da contabilidade.

\subsection{Focos de publicação e abordagem da linguagem dos artigos}

$\mathrm{Na}$ Tabela 5 apresenta-se uma síntese da composição dos achados, evidenciando o foco temático da publicação e a abordagem da linguagem dos artigos pesquisados nas áreas de Contabilidade para Usuários Externos e Mercados Financeiro, de Crédito e de Capitais.

Tabela 5 - Foco temático versus abordagem da Linguagem

\begin{tabular}{|c|c|c|c|c|c|c|c|c|}
\hline \multirow{13}{*}{ 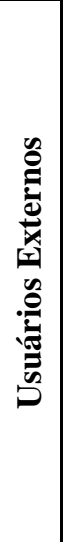 } & \multirow{2}{*}{ Foco Temático } & \multicolumn{2}{|c|}{ Sintática } & \multicolumn{2}{|c|}{ Semântica } & \multicolumn{2}{|c|}{ Pragmática } & \multirow{2}{*}{$\begin{array}{c}\text { Total de } \\
\text { artigos }\end{array}$} \\
\hline & & Quant & $\%$ & Quant & $\%$ & Quant & $\%$ & \\
\hline & Teoria da Contabilidade & 7 & 12,1 & 14 & 24,1 & 37 & 63,8 & 58 \\
\hline & Contabilidade Societária & 6 & 20,0 & 8 & 26,7 & 16 & 53,3 & 30 \\
\hline & Convergência de Normas & 31 & 83,8 & 6 & 16,2 & & & 37 \\
\hline & Balanço Social (DVA, MA, RH) & 5 & 8,1 & 16 & 25,8 & 41 & 66,1 & 62 \\
\hline & Capital Intelectual & & & 4 & 44,4 & 5 & 55,6 & 9 \\
\hline & Contabilidade Pública e do Terceiro Setor & 6 & 25,0 & 11 & 45,8 & 7 & 29,2 & 24 \\
\hline & Auditoria Independente & 7 & 22,6 & 9 & 29,0 & 15 & 48,4 & 31 \\
\hline & Análise das Demonstrações Contábeis & 1 & 3,2 & 16 & 51,6 & 14 & 45,2 & 31 \\
\hline & Rec. dos Efeitos Inflacionários & & & 1 & 50,0 & 1 & 50,0 & 2 \\
\hline & Contabilidade Tributária & 4 & 66,7 & 1 & 16,7 & 1 & 16,7 & 6 \\
\hline & Governança Corporativa & 2 & 8,7 & 14 & 60,9 & 7 & 30,4 & 23 \\
\hline \multirow{6}{*}{ 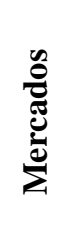 } & Auditoria & & & 1 & 100,0 & & & 1 \\
\hline & Finanças Corporativas de CP e LP & 14 & 6,1 & 146 & 63,2 & 71 & 30,7 & 231 \\
\hline & Valuation & 1 & 5,3 & 12 & 63,2 & 6 & 31,6 & 19 \\
\hline & Gestão de Riscos & 1 & 3,0 & 15 & 45,5 & 17 & 51,5 & 33 \\
\hline & Mét. Quant. Aplicados à Cont. Societária & & & 4 & 50,0 & 4 & 50,0 & 8 \\
\hline & Finanças Pessoais & & & 1 & 100,0 & & & 1 \\
\hline \multicolumn{2}{|c|}{ Total } & 85 & 14,0 & 279 & 46,0 & 242 & 39,9 & 606 \\
\hline
\end{tabular}

Fonte: Dados da pesquisa.

De modo geral, os resultados da Tabela 5 mostram que existe uma afinidade entre o foco temático dos artigos publicados nos periódicos científicos e a abordagem da linguagem utilizada nestes focos, ou seja, os artigos com focos temáticos da área de usuários externos utilizam-se principalmente da abordagem da linguagem pragmática, e os artigos dos focos temáticos da área de mercados financeiro, de crédito e de capitais adotam a abordagem da linguagem semântica.

Na abordagem sintática destacam-se dois focos temáticos: Convergência de Normas e Contabilidade Tributária, ambos da área de Contabilidade para Usuários Externos. Os artigos com foco em convergências de normas, em sua grande maioria, apresentam abordagens sintáticas, somando 31 artigos dos 37 desse foco temático. Dias Filho (2009) compartilha 
dessa constatação ao mencionar que no nível sintático, a compreensão das informações contábeis se dá à luz do conjunto de normas e princípios que regem a sua produção.

$\mathrm{Na}$ abordagem semântica, os artigos que predominaram (146) foram os voltados para a área de Finanças Corporativas de Curto Prazo e de Longo Prazo. Esse resultado pode ser explicado ao considerar que a proposta dos estudos semânticos consiste em descrever, explicar ou predizer a natureza dos objetos ou eventos contábeis (COLAUTO, 2005).

Em relação à abordagem pragmática, a maior parte dos trabalhos refere-se ao Balanço Social, que engloba temas relacionados à Demonstração do Valor Adicionado, meio ambiente e recursos humanos. Isso se deve ao fato que pesquisas nesse enfoque se preocupam com a transparência e divulgação de informações úteis e pertinentes aos usuários (HENDRIKSEN; VAN BREDA, 2011).

Observa-se ainda que especialmente o foco temático teoria da contabilidade possui em sua maioria artigos com abordagem pragmática. Esse achado confirma a teoria de Kam (1990), pois o autor cita que a Teoria Contábil tem maior identificação com a orientação pragmática. Isso ocorre devido à própria natureza da Contabilidade e ao seu objetivo de satisfazer necessidades informativas dos usuários.

Os achados do estudo em parte condizem com a teoria, porém nota-se que há predominância da linguagem semântica em relação às demais. Isso pode ser um indicio de mudança nas pesquisas quanto a abordagem utilizada, visto que em pesquisa realizada na década passada por Theóphilo (2000), constatou que são raros os estudos que se propõem a verificar o significado da linguagem.

\section{CONSIDERAÇÕES FINAIS}

A contabilidade enquanto linguagem dos negócios pode ser percebida sob as abordagens sintática, semântica e pragmática. Cada uma dessas abordagens visa elucidar as diferentes facetas da linguagem contábil. A sintática, cujo foco está na produção da informação, utiliza-se apenas da lógica, sua preocupação central é como as informações financeiras são apresentadas e comunicadas aos usuários. A semântica busca melhorar a compreensão da informação por parte do usuário. A pragmática atém-se a utilidade da informação e seu efeito sobre quem a recebe.

Neste sentido, o estudo objetivou investigar a linguagem contábil adotada na sustentação teórica das publicações em periódicos científicos brasileiros no período 20012012, relativas à Contabilidade para Usuários Externos e a Mercados Financeiro, de Crédito e de Capitais. Para tanto, realizou-se um levantamento dos artigos publicados nas áreas de Contabilidade para Usuários Externos e de Mercados Financeiro, de Crédito e de Capitais no período 2001-2012 em periódicos nacionais de contabilidade dos estratos A2, B1 e B2 do Qualis CAPES, cujo recorte deve ser considerado uma limitação da pesquisa.

Por meio da análise de conteúdo verificou-se que os periódicos analisados são similares nas publicações segundo a sua abordagem da linguagem contábil preconizada. As linguagens semântica e pragmática se sobressaem à linguagem sintática. Esta evidência sugere uma mudança de abordagem nas pesquisas contábeis, pois a pesquisa realizada por Theóphilo (2000) em período anterior a esta revelou que as pesquisas em contabilidade em sua maioria priorizam investigações de ordem pragmática, por outro lado, os trabalhos que se propõem ao estudo semântico são raros. Também se contrapõe à afirmação de Kam (1990), de que os estudos da área contábil carecem de aspectos semânticos. A predominância da linguagem semântica em relação às demais, constatada na presente pesquisa, sugere que os estudos em contabilidade tiveram uma evolução quanto à abordagem da linguagem contábil, visto que a semântica busca melhorar a compreensão da informação por parte do usuário.

Outro fato relevante foi observado ao se analisar a relação temática dos artigos com a 
linguagem. Os achados mostram que artigos que investigaram assuntos relacionados aos usuários externos são mais propensos a utilizarem a abordagem pragmática. Por outro lado, artigos que buscam elucidar problemas relativos à área de Mercados Financeiro, de Crédito e de Capitais se utilizam principalmente da abordagem semântica. Destaca-se, ainda, que artigos com foco temático em convergências de normas apresentaram em sua sustentação teórica principalmente a abordagem da linguagem sintática, somando 31 artigos do total de 37 com este foco. Na abordagem semântica o foco que se destacou foi Finanças Corporativas. Em relação à abordagem pragmática o foco recaiu nos artigos que tratam de assuntos ambientais e sociais, ou seja, o foco Balanço Social. Tais achados se sustentam na teoria, conforme mencionado no referencial teórico e na análise dos resultados.

Considerando-se as limitações da pesquisa, pode-se afirmar que há indícios de que as abordagens da linguagem da contabilidade estão evoluindo de forma gradual, passando a ter maior profundidade. Pois, como afirma Theóphilo (2000), pesquisas com orientação semântica são complexas e oferecem dificuldades para sua realização. No estudo pode-se verificar que pesquisas com esta orientação tiveram maior ênfase desde a publicação do trabalho do referido autor. Kam (1990) destaca que a evolução da ciência ocorre por meio da intensificação das pesquisas, o que se comprova, pois o número de publicações cresceu a cada ano, além de que as pesquisas estão apresentando uma evolução gradual. Assim, recomendase para futuros estudos analisar o desenvolvimento das abordagens da linguagem da contabilidade e os possíveis fatores que possam estar contribuindo para esta evolução.

\section{REFERÊNCIAS}

ANTHONY, Robert Newton. Contabilidade gerencial. São Paulo: Atlas, 1972.

BARDIN, Laurence. Análise de conteúdo. 3. ed. Lisboa: Editora 70, 2004.

BEDFORD, Norton M; BALADOUNI, Vahe. A communication theory approach to accounting. The Accounting Review, Sarasota, p. 650-659, 1962. Disponível em: <http://www.jstor.org/stable/242352>.

BRASIL. Lei n. 11.638, de 28 de dezembro de 2007. Altera e revoga dispositivos da Lei $n$. 6.404, de 15 de dezembro de 1976, e da Lei n. 6.385, de 7 de dezembro de 1976, e estende às sociedades de grande porte disposições relativas à elaboração e divulgação de demonstrações financeiras. Disponível em: <http://www.planalto.gov.br>. Acesso em: 15 jan. 2013.

BRYMAN, Alan. Social research methods. 3. ed. Oxford University Press, 2008.

CARDOSO, Ricardo Lopes; MENDONÇA NETO, Octávio Ribeiro de; RICCIO, Edson Luiz; SAKATA, Marici Cristine Gramacho. Pesquisa científica em contabilidade entre 1990 e 2003. Revista de Administração de Empresas, v. 45, n. 2, p. 34-45, abr./jun. 2005. http://dx.doi.org/10.1590/S0034-75902005000200004

COLAUTO, Romualdo Douglas. Metodologia para evidenciar a influência de accruals no lucro contábil por meio da Demonstração de Origens e Aplicações de Recursos. 2005, 215f. Tese (Doutorado em Engenharia de Produção) - Universidade Federal de Santa Catarina, UFSC, Santa Catarina, 2005.

COLAUTO, Romualdo Douglas; BEUREN, Ilse Maria. Avaliação do capital intelectual na perspectiva da tridimensionalidade da linguagem contábil. Base (Unisinos), v. 2, n. 2, p. 85- 
$101,2005$.

COLAUTO, Romualdo Douglas; BEUREN, Ilse Maria; MEDINA, Enrique Alfonso Muñoz. La tridimensionalidad del lenguaje contable en la mensuración de activos con énfasis en la evaluación del capital intelectual. Produção Online, v. 5, n. 3, set. 2005. http://dx.doi.org/10.14488/1676-1901.v5i3.357

COMISSÃO DE VALORES MOBILIÁRIOS (CVM). Deliberação CVM nº 647, de 2 de dezembro de 2010. Aprova o Pronunciamento Técnico CPC 37(R1) do Comitê de Pronunciamentos Contábeis, que trata da adoção inicial das normas internacionais de contabilidade. Disponível em:

<http://www.cvm.gov.br/asp/cvmwww/atos/Atos_Redir.asp?Tipo=D\&File=Idelildeli647.doc >. Acesso em: 14 ago. 2013.

COMISSÃO DE VALORES MOBILIÁRIOS (CVM). Deliberação CVM n⿳ 651, de 16 de dezembro de 2010. Aprova o Pronunciamento Técnico CPC 43(R1) do Comitê de Pronunciamentos Contábeis, que trata da adoção inicial dos Pronunciamentos Técnicos CPC 15 a 41. Disponível em:

$<$ http://www.cvm.gov.br/asp/cvmwww/atos/Atos_Redir.asp?Tipo=D\&File=/delildeli651.doc >. Acesso em: 14 ago. 2013.

COORDENAÇÃO DE APERFEIÇOAMENTO DE PESSOAL DE NÍVEL SUPERIOR CAPES. Qualis periódicos. Disponível em: <http://www.capes.gov.br/avaliacao/qualis>. Acesso em: 09 ago. 2013.

COSTA, Alessandra Cristina Oliveira.; THEÓPHILO, Carlos Renato. Mensuração de ativos: uma discussão sob a ótica da teoria contábil como linguagem. In: ASIAN PACIFIC CONFERENCE ON INTERNATIONAL ACCOUNTING ISSUES, 13., 2001, Rio de Janeiro. Anais... Rio de Janeiro: FEA/USP, 2001. CD-ROM.

DIAS FILHO, José Maria. A linguagem utilizada na evidenciação contábil: uma análise de sua compreensibilidade à luz da teoria da comunicação. Revista Contabilidade \& Finanças, v. 13, n. 24, p. 38-49, jul./dez. 2000. DOI: http://dx.doi.org/10.1590/S141392512000000200003

DIAS FILHO, José Maria. Dimensões semióticas da contabilidade: uma abordagem da teoria da contabilidade. Revista de Contabilidade da UFBA, v. 3, n. 1, p.3 - 4, jan./abr. 2009.

DIAS FILHO, José Maria; NAKAGAWA, Masayuki. Reflexões sobre a dimensão semiótica da análise de balanços: uma contribuição à otimização de decisões de crédito. Revista de Contabilidade da UFBA, v. 6, n. 1, p. 33-47, jan./abr. 2012.

http://www.portalseer.ufba.br/index.php/rcontabilidade/article/view/6194.

ETHERIDGE, Harian Lynn. An examination of Semiotic Theories of Accounting Accruals. Unpublished Ph. D. dissertation, Louisiana State University, 1991.

FERREIRA, Aurélio Buarque de Holanda. Novo dicionário Aurélio da língua portuguesa. 2. ed. Rio de Janeiro: Nova Fronteira, 1986.

FINANCIAL ACCOUNTING STANDARDS BOARD (FASB). Statement of Financial 
TRIDIMENSIONALIDADE DA LINGUAGEM CONTÁBIL EM PUBLICAÇÕES DE PERIÓDICOS CIENTÍFICOS BRASILEIROS

Accounting Standards $n^{\circ}$ 4. Impact on corporate risk and insurance management.

Stamford, Connecticut, 1980.

GAFFIKIN, Michael. The critique of accounting theory. Accounting \& Finance Working Papers, School of Accounting and Finance, University of Wollongong, n. 6/25, p. 1-21, 2006. Disponível em: <http://ro.uow.edu.au/cgi/viewcontent.cgi?article=1040\&context=accfinwp > Acesso em: 11 abr. 2013.

HENDRIKSEN, Eldon. S.; VAN BREDA, Michael. F. Teoria da contabilidade. São Paulo: Atlas, 2010.

IJIRI, Yuji. Theory of accouting measurement. Studies in Accounting Research 10. Sarasota: American Accouting Asociation, 1975.

ILUFI, Oscar Manuel Vergara. Teoria da comunicação e teoria da semiótica: sua incorporação ao processo de formação universitária do contador no Chile. In:

CONFERÊNCIA ACADÊMICA PERMANENTE DE PESQUISA EM CONTABILIDADE, 11., 2000, Talca. Anais... Talca, 2000. Disponível em:

<http://www2.rio.re.gov.br/cgm/textos_teoria_semiotica.pdf>. Acesso em: 11 abr. 2013.

KAM, Vernon. Accouting theory. 2. ed. Califórnia: John Wiley \& Sons, 1986.

KILLIAN, Sheila. No accounting for these people: Shell in Ireland and accounting language. Critical Perspectives on Accounting, v. 21, n. 8, p. 711-723, 2010.

LAVOIE, Don. The accounting of interpretations and the interpretation of accounts: The communicative function of "the language of business". Accounting, Organizations and Society, v. 12, n. 6, p. 579-604, 1987. http://dx.doi.org 10.1016/0361-3682(87)90010-9

LEWANDWSKI, Theodor. Linguistisches waterbuck. 3. ed. Stuttgart: UTB, 1982.

LILLO-MARTIN, D. Sign Language: Syntax, In: Editor-in-Chief: Keith Brown, Editor(s)in-Chief, Encyclopedia of Language \& Linguistics, Second Edition, Elsevier, Oxford, 2006, p. 351-353. http://dx.doi.org/10.1016/B0-08-044854-2/00241-8

MARTINS, Gilberto Antônio; THEÓPHILO, Carlos Renato. Metodologia da investigação científica para ciências sociais aplicadas. 2. ed. São Paulo: Atlas, 2009.

MORRIS, Charles W. Fundamentos da teoria dos signos. Trad. Paulo Alcoforado e Milton José Pinto. Rio de Janeiro, Eldorado Tijuca, São Paulo: Edusp, 1976.

NAKAGAWA, Masayuki; DIAS FILHO, José Maria. A contabilidade sob o enfoque sociológico: uma abordagem das teorias semióticas e da comunicação. Augusto Guzzo Revista Acadêmica, n. 5, p. 13-22, 2002. Disponível em: <http://www.fics.edu.br/index.php/augusto_guzzo/article/view/109>. Acesso em: $11 \mathrm{abr}$. 2013.

SANTAELLA, Lúcia. O que é semiótica. 14. ed. São Paulo: Brasiliense, 1998.

SHANNON, Claude; WEAVER, Warren. The mathematical theory of communication. 
Urbana, Illinois: University of Illinois, 1949.

STAMPER, Ronald K. Towards a theory of information: Mystical fluid or a subject for scientific enquiry? The Computer Journal, v. 28, n. 3, p. 195-199, 1985.

http://comjnl.oxfordjournals.org/content/28/3/195.full.pdf.

TEJAY, Gurvirender; DHILLON, Gurpreet; CHIN, Amita Goyal. Data quality dimensions for information systems security: a theoretical exposition (invited paper). Security Management, Integrity, and Internal Control in Information Systems, International Federation for Information Processing (IFIP), v. 193, p. 21-39, 2006.

http://dx.doi.org/10.1007/0-387-31167-X_2

THEÓPHILO, Carlos Renato. Uma abordagem epistemológica da pesquisa em contabilidade. 2000. 141f. Dissertação (Mestrado em Controladoria e Contabilidade) Universidade de São Paulo, São Paulo, 2000.

WERNER, O. Sapir-Whorf Hypothesis. In: ASHER, R.E.; SIMPSON, J.M.Y. (editors.). The encyclopedia of language and linguistics. Oxford: Pergamon Press, 1994. Vol. 7. 